Original Article

\title{
Cadastral Survey Plans Management System: A Deliberative Report on Possibility of Utilizing Innovative Technologies on Managing Cadastral Survey Plans and Mapping in Sri Lanka
}

\author{
Mendis L. N.J ${ }^{1}$, Gunasekara S. ${ }^{2}$ \\ \#Department of Information Technology, CINEC Campus \\ Millennium Drive, IT Park, Malabe, Sri Lanka \\ ${ }^{l}$ lakshan_mendis@yahoo.com
}

\section{Abstract}

This report discusses the review of the Cadastral Survey Plans Management System in the context of the research project that is aimed at improving the management and security of the system. The research efforts of the project are aimed at facilitating the Cadastral Survey Plans Management System by justifying the possibility of utilizing innovative technologies on managing cadastral survey plans and mapping in Sri Lanka. In order to overcome and avoid complexity of problems and issues, various techniques and tools will be used. While the research section of the project is bounded with the human interaction of the society, building a mutual relationship with the employees of the Survey Department and the clients will be one of the primary focus of the proposed project and it will lead to understand the structural aspects of the department as well. Thus, the project was focussed on decision procedures, data security and information sharing. When considering the data security and information sharing in the software artefact, responsibilities will be divided according to the decision procedures of the organization or department. The goal of implementing Cadastral Survey Plans Management System is to induce the
\end{abstract}

manpower and paperwork into minimum level and empower the security of the department.

\section{Keywords: Cadastral Survey, Encroachment Survey, Mapping, Tenement Lists}

\section{Introduction}

As the oldest Government Department of Sri Lanka, established on $2^{\text {nd }}$ August 1800 , the Sri Lanka Survey Department is responsible for national surveying and mapping. By the end of the 19th century, Survey Department engaged on a wider range of surveying functions including Block Surveys for land settlement, Topography Surveys for mapping,

Application/Miscellaneous Surveys including Irrigation Surveys, Road/Railway Surveys, and Forest Surveys etc. [1]. However, being one of the oldest departments in Sri Lanka and having a massive database of survey plans, tenement lists, and mapping information, it has been difficult to maintain various survey information properly for a long period of time.

by researching the Possibility of Utilizing Innovative Technologies on Managing Cadastral Survey Plans and Mapping in Sri Lanka. 


\section{Literature Review}

According to the Chang, Young $\mathrm{Ku}$ Kang, Dong Hyun Kang and In Joon [2], in the current conventional computerization management of the cadastral system in South Korea is operated with raster map data. However, that data was difficult to use along with the National Geographic Information System in South Korea. Therefore, they decided that, for a more accurate map management, the cadastral map management system must be operated with vector data. Cadastral map computerization was built on related geographic information system. This system was used "Gauss Double Projection" for the length of lands and accurate division of area. Even users decided the length and area, it will be difficult to manage the whole cadastral map due to the discord of map connection. When considering the time before the Cadastral map computerization, the people who provided the land utilization confirmation document to the offices, spent almost over 30 minutes from application to acquirement. Also, cadastral mapping was directly related to private properties and government needed a way to gather necessary information from civilians.

The importance of Cadastral Map Computerization was to reduce the level of inefficiency in the Korean Cadastral Survey Corporation management system. The main affair of the Cadastral Map Management System in South Korea was the acquirement of land utilization confirmation document and merge-divide work of cadastral. The implementation of this project will have been a positive effect as it sought to solve management problems in the Corporation. When comparing with the former cadastral system, it spent more than 40 - 50 minutes for cadastral map acquirement and after the implementation of the Cadastral Map Computerization, computations processed within 10 minutes and efficiency of affair rose.

According to the Byong-Nam Choe, Mi-Jeong Kim, Kwon-Han Lee and Yoon-Hee Jeong [3], information on various maps and land documents, which are managed by the land administration in South Korea was inaccurate and discordant. Furthermore, people had to travel far to visit a city hall, country office or district office to obtain information on land use regulations. However, the process is taken several months for the information produced by municipalities. Considering the present status of the land data on digital topographical maps have an enormous amount of information and it includes a lot of superfluous information which interferes with the construction and maintenance of a spatial database. One of the other identified drawbacks in managing land information more accurately was a lack of attribute data on topography due to land data was originated and relied on the paper maps.

To solve the identified problems in land administration in South Korea, the Ministry of Construction and Transportation (MOCT) implemented the project of Land Management Information System (LMIS) in 1997. The LMIS has tripartite objectives such as to provide land information to people upon request, to enhance the productivity of public land administration and establish rational land policies.

When considering worldwide similar solutions, a Singaporean company has developed a Cadastral System that supports digital cadaster. According to the Kean Huat Soon, Derick Tan and Victor Khoo [4] who developed the Singaporean Cadastral System, this digital cadaster encodes cadastral information in 
digital format which allows for automation and returns high productivity. This System based on the Intergovernmental Committee on Surveying and Mapping's ePlan model, which already has been implemented in Australia and New Zealand. However, registered surveyors can check all the information through the web portal before the authority's inspection and approval. By using this product, engineers expected to reduce turnaround times and speed up the overall approval process. Considering its key features,

- Adding the vertical dimension and time.

- Adopting an open standard for automation and data interoperability.

- Providing a proactive communication platform with registered surveyors.

The current cadastral system was not capable of representing complex and much newer information that involve the developments in Singapore.

By implementing the proposed Cadastral Survey Management System in Land Survey Division of Singapore Land Authority, it helped to achieve automation and data interoperability, 3D and provenance and built a proactive communication platform for registered surveyors.

All the major countries throughout the world since the last decades have been establishing digitalized cadastral systems. Throughout the world, it is recognized as an important facility which helps to make the economic and sustainable development stable. Cadastral Management Systems should be able to adjust for the multi-purposes and meet the modern IT environment.

expected to increase to 1286 million people by the year 2020 and considering the population growth of Malaysia, it is also expected to reach
Current cadastral maps are based on handdrawn property maps and mostly these maps could be damaged due to the prolonged time of storage. Plans details could be faded or destroyed by several reasons and due to the analog maps and the accuracy of the cadastral maps could be different from few centimetres in some urban and rural areas.

As a solution to the above-identified issues, Prof. Stig Enemark and Prof. Hans Sevatdal [5] have published an opinion by researching "Is Land Information System and Planning decentralization is a significant key to sustainable development in Denmark?" Proposed cadastral infrastructure was empowered on land administration and land management systems.

- The proposed cadastral project assisted in valuation, taxation, land management, planning and administration.

- Enabled sustainable development and environmental improvement.

- Professionals in the IT world have already argued that within the next decade, such land information systems will perform an integral part of the model of a man-made environment.

- Provided land information to the financial and business sectors, land administration, environmental management, urban systems, and community information systems.

- Accuracy of the digital cadastral maps, the effectiveness of the sectors will be improving day by day.

According to the Tan Liat Choon, Dr. Khadijah Binti Hussin and Sr. Ernest Khoo Hock Oon [6], the urban population of Asia is

31 million people by 2020 . Due to the rapid increases for development processes and technical purposes, the existing Malaysian 
Cadastral System is unsuitable for representing the current situations.

The existing Malaysian Cadastral System is insufficient to meet the expected productivity of the high-density developments in urban areas. Due to the legal changes in the land registry has not been made in accordance with the complexity of the developments, some of the buildings have been built illegally or crossing boundary edges. There are difficulties to register the ownership of land and properties and existing legal registration process for 3D property in Malaysia is time-consuming. Experience in land registration and legislation shows there is insufficient property legislation. The utilization of lands in Malaysia has not followed the process of the proper Malaysian Cadastral System.

The land register considered one of the most critical documents in Malaysian Registration System. However, with the implementation of the new Cadastral Management System, the hard copy of the registry replaced by a computerized land registry that enabled the proprietor to transfer, change the land, or grant rights of easements.

\section{Methodology}

The success or the failure of the software is influenced by the quality of the requirements. Therefore, identification of the efficient software requirements is one of the key challenges to develop high quality software solutions. Requirement elicitation techniques can be divided into four categories according to their nature of communication. Such as traditional, contextual, collaborative, and cognitive.

\section{A. Traditional}

An Interview is a method of identifying the opinions of clients of the organizations by face-to-face conversations. With the guidance and support of Mr. N.R.L Mendis (Rtd. Superintendent of Surveys) and $\mathrm{Mr}$ Wikkramarachchi (Rtd. Add. Surveyor General), the interview process was conducted successfully and by selecting one of the three types of interviews such as Closed-Ended, Open-Ended, and Probing Questions, the Business Analyst was able to prepare and generate a report within 48 hours. Most importantly this interview process was intended to discover their expectations of the system, business aspects, critical thinking, and encourage the interviewee to open their personal thoughts on specific topics.

Questionnaires are a technique of eliciting requirements from many people within lesser cost and time. This technique is based on electronics and papers. Therefore, these questionnaires could be a set of written or typed questions on emails and printed sheets. The success of the questionnaire process is depending on how well the questionnaires are design and the skills of the interviewer who conduct the interview session. Considering the environmental facts, it could be suitable for remote locations. Therefore, the Questionnaire was distributed with the assistance of Surveyors and employees of the Divisional and District Survey Offices. Thus, Project objectives were identified in accordance with the suggestions and feedbacks expressed in the questionnaire. 


\section{B. Collaborative}

Joint Application Development (JAD) is considered as one of the processes that expedite business solutions in the software development environment. After requesting a meetup from the Divisional Survey Office Gampaha, this was followed by a meeting with the Superintendent of Surveys, Assistant Superintendent of Surveys and Surveyors.

When considering the physical involvement of the JAD session, it encourages the teamwork of software architects, software developers, stakeholders, and others who related to the business and software processes to precisely depict the aspects of the business need where they can jointly develop a solution and the success of the session depends on the leadership among the participants who tries achieving group synergy during the JAD session. The JAD session was focused on business problems rather than the technical details. While the JAD offered a team-oriented approach in the software and business environment, it enabled the spirit of the partnership and effective than other traditional business meetups.

\section{Cognitive}

Document Analysis is a process of analysing the documents related to the problem and gather necessary information. It is considered as one of the best requirement elicitation techniques to gather information and the business analyst of the particular organization should be able to go through all the documents which are related to the software process and analyse the current system architecture as well. Furthermore, this technique helps business analysts to prepare questions for validating the correctness of information.

According to proper procedures and legal permissions obtained from the officers in charge of the relevant divisions of the Survey Department in Sri Lanka, it was possible to inquire into various official documents related to the proposed artefact such as Cadastral Survey Plans, Tenement Lists, Field Books, Amendments, Department Survey Regulations, Plans and Diagrams, Standing orders, Survey Acts, Temple Lands Registration Ordinance, Registration of Title Acts, Urban Development Authority Regulations for Subdivisions of Lands.

\section{Feasibility Study}

When it comes to the Feasibility Report, considering the project aspects and the context of the project, research studies were inclined more on Technical Feasibility and Economic Feasibility. According to the research facts, the familiarity with the applications of Survey Department was moderately low and it was impossible to connect Land Reform Commission (LRC), Road Development Authority (RDA), and Private Cadastral Survey Plan Information together. Also, Surveyors record all the survey information manually on field books. However, familiarity with the technology of the Survey Department was moderately high, both employees and senior officers had a good understanding of what the system should do. When considering the compatibility with the existing technology, it was also moderately high due to the advanced survey equipment used, computer labs, and knowledgeable individuals who could operate the proposed artefact.

Although the Survey Department was empowered with knowledgeable individuals and advanced technological equipment, there were still several shortcomings that make it impossible to implement the proposed artefact. Therefore, after a systematic, formal, and transparent Economic Feasibility investigation, 
could fulfil the necessary resources and system needs through a properly designed budget plan.

Artefact

It is always debatable the possibility of utilizing innovative technologies on managing cadastral survey plans and mapping in Sri Lanka. Doubt and fear of failure leads to the edge of the bridge where the boundary lays between the 3rd world countries and the rest of the world. Now more than ever, the world needs cutting edge defensive techniques to face challenges, overcome drawbacks and prevent the threats before they occur. Therefore, throughout the application development, the research study aims to minimize the chances of having threats from intruders and secure the application and data responsibly. Thus, to obtain expected outcomes, the proposed artefact was designed and applied following innovative technological features.

1) Desktop Application:

- Microsoft Visual Studio 2019

- Microsoft C\# Programming Language

- MySQL Database

- Bunifu Framework

- GMAP.NET

- IronOcr

- LiveCharts

- MessagingToolkit.QRCode

- Spire.Pdf

- Twilio

2) Features:

- Encode and Decode QR

- Encrypt and Decrypt Cadastral Survey Information

- OTP Message Service

- SSL Certification on Email
- Live Mapping - Latitude, Longitude, Routes, Add Points, Area by Polygon, Load Locations, Clear and Remove Points

- Screenshot Facility

- Live Charts and Report Generating Revenue, Number of Lots, Extent and Topography

- Open and Extract PDF to Word Format | Search and Highlight Texts

- Indicating Error Messages and Password Reset Options

- Backup and Restore Database

\section{Testing/ Results}

\section{A. Bimsaviya $|L R C| R D A$}

According to the research facts, information, and alphanumeric data which were gathered from various requirement elicitation techniques, helped designing a platform that could manage imperative and crucial cadastral survey information in Bimsaviya Project, Land Reform Commission, and Road Development Authority.

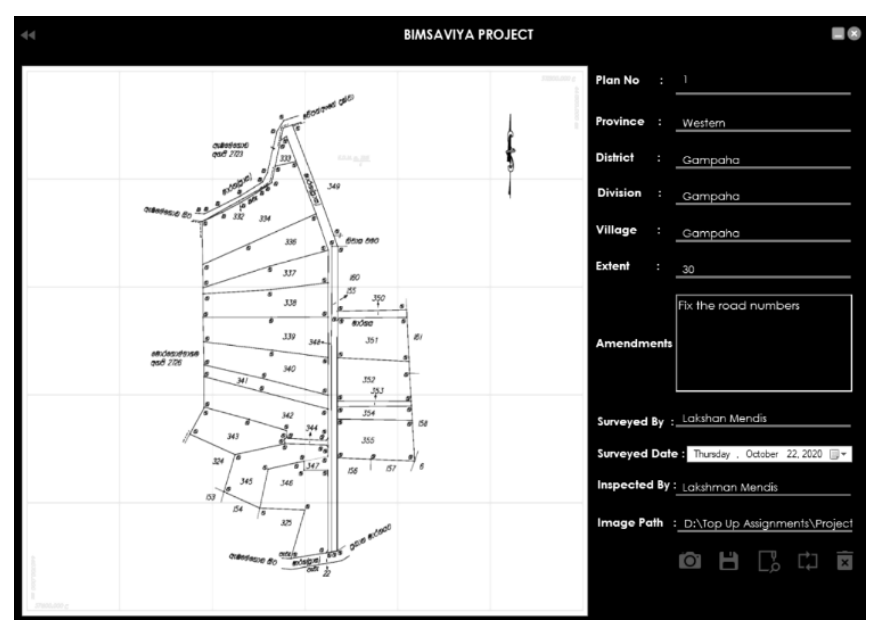

Fig. 1 Managing Bimsaviya Project Survey Information 


\section{B. Mapping}

The Mapping can be considered as the [35] simplest way to find the details before log into the various types of investment projects on lands. The aim of publishing geospatial information in Google Map is, to fast track searching lands free of restrictions for better management of lands.

When developing the mapping feature which is empowered with the Live Mapping, Latitude, Longitude, Routes, Add Points, Area by Polygon, Load Locations, Clear and Remove Points features, allow permission to Surveyors and Superintendent of Surveyors to search locations based on specific criteria.

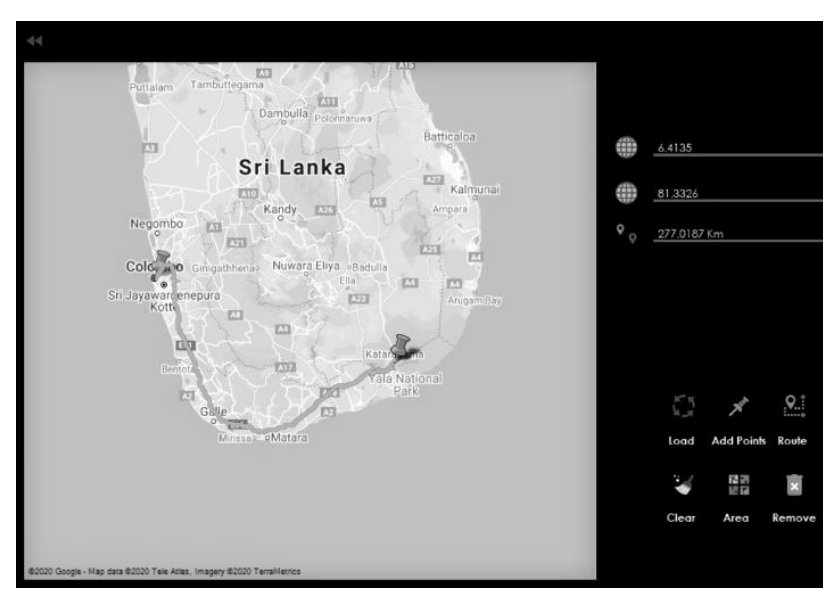

Fig. 2 Search Locations and Calculate Distance According to given Latitude and Longitude Values

When considering the types of various algorithms, Bellman Ford, A*, Floyd Warshall, Depth-First-Search (DFS), Breadth-FirstSearch (BFS), and Dijkstra are considered the most popular algorithms in finding shortest path.

Bellman Ford Algorithm (BFA) is used to find the shortest path from the source vertex to all other vertices in a graph [26]. This algorithm depends on the relaxation principle where the shortest distance for all vertices is gradually replaced by more accurate values until eventually reaching the optimum solution. However, BFA does not use a priority queue [27]. Instead, it repeatedly loops over all edges and updating the distances to the start node. BFA considered as a Dynamic Algorithm and it can calculate the negative directed edges [21], can minimize the cost when network was built by not building lot of router paths as it can find the shortest path from one node to another. Besides that, when used in Routing Information Protocol (RIP) a slow response to changes in network topology resulting from slow updates passed from the RIP device to the next device. These flaws lead to an attempt to use idle tracks that waste time and network resources.

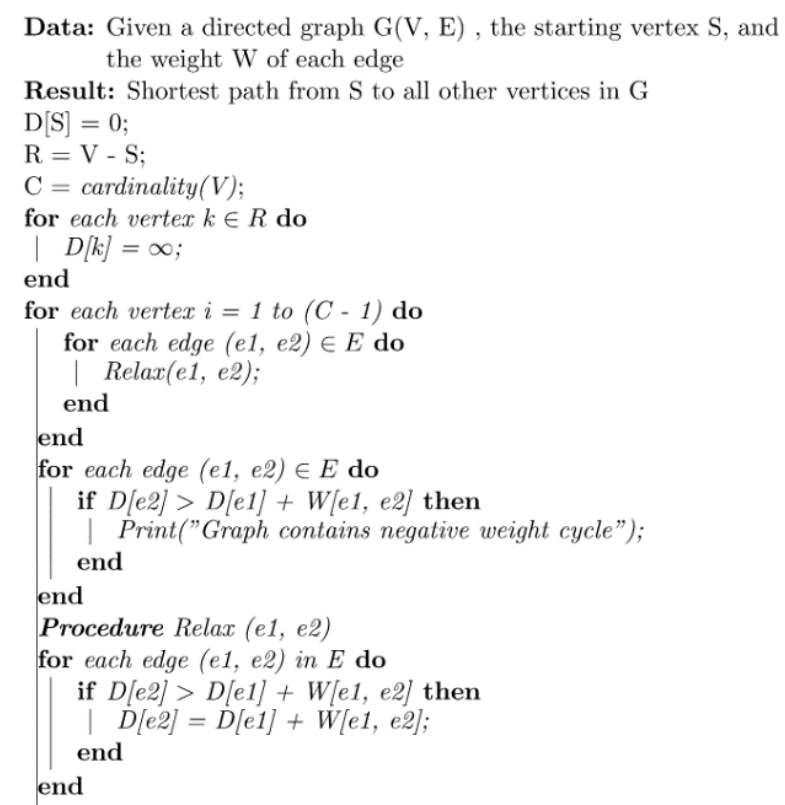

Fig. 3 Pseudocode: Bellman Ford Algorithm 

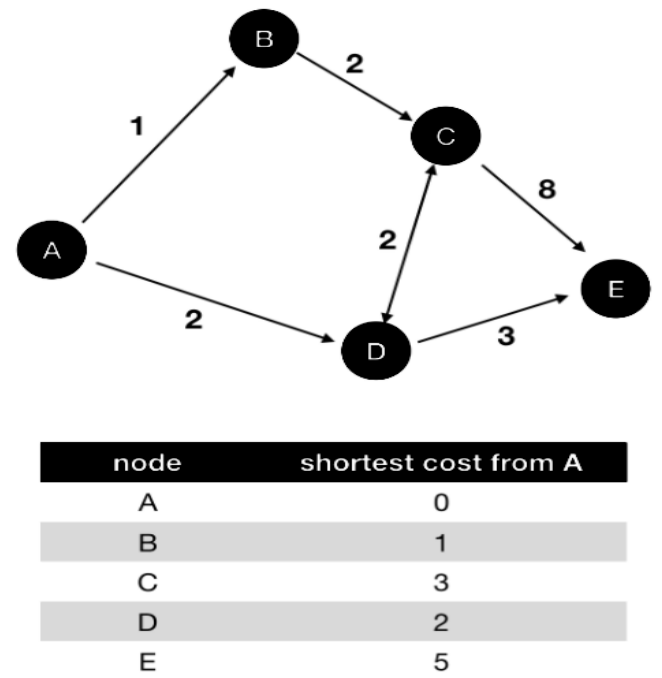

Fig. 4 Nodes based on Bellman Ford Algorithm

Another algorithm to consider in finding the shortest path is $A^{*}$ Algorithm. $A^{*}$ is based on using heuristic methods and widely recognised as an optimal and complete algorithm. According to the Akash Jain [30], the optimal algorithm finds the least cost path from the source location to the destination while complete algorithm finds all the paths that are available from the source location to the destination. Considering the disadvantages of the $A^{*}$ algorithm, it is said that it is a bit slower than the other competitive algorithms.

$\mathrm{f}(\mathrm{n})=$ Total estimated cost of path through node $n$

$\mathrm{g}(\mathrm{n})=$ Cost to reach node $\mathrm{n}$

$\mathrm{h}(\mathrm{n})=$ Estimated cost from $\mathrm{n}$ to destination

$$
\mathrm{f}(\mathrm{n})=\mathrm{g}(\mathrm{n})+\mathrm{h}(\mathrm{n})
$$

The Floyd-Warshall Algorithm (FWA) is a classic dynamic algorithm which compute the length of all shortest paths between any two vertices in a graph [32].

for $\mathrm{k}=1 \ldots \mathrm{n}$ do

for $\mathrm{i}=1 \ldots \mathrm{n}$ do

for $\mathrm{j}=1 \ldots \mathrm{ndo}$

$m[i, j]=\min (m[i, j], m[i, k]+m[k, j])$ $\mathrm{m}=$ Matrix

$\mathrm{k}=$ Iteration 1 to $\mathrm{n}$

$\mathrm{i}=$ First Point $\mathrm{v}_{\mathrm{i}}$

$\mathrm{j}=$ First Point $\mathrm{v}_{\mathrm{j}}$

The aim of the algorithm is to compare each route variation with the distance from each source to the destination and accumulates the distance between the nodes that are passed [32] When searching the shortest path, all iterations (k) will be used to make n matrix. Therefore, the process used is slower than some of the competitive algorithms. Apart from that FWA can only find the shortest path when there are no negative cycles, and it does not return the details of the paths.

According to Google, Dijkstra's Algorithm (DA) finds the [25] shortest path between two places and it picks the unvisited vertex with the lowest distance, calculates the distance through it to each unvisited neighbour and updates the neighbour's distance if smaller.

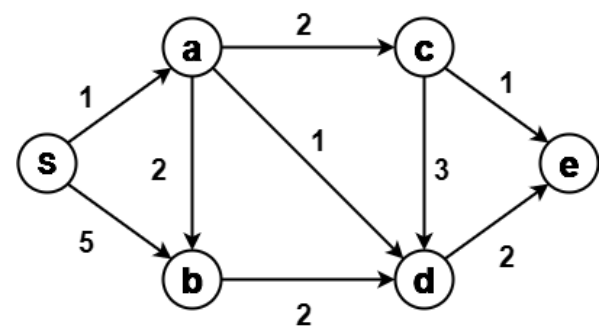

Fig. 5 Nodes based on Dijkstra Algorithm

DA is an iterative algorithm that provides the shortest path from one particular source node to all other nodes in the graph and also considered as the greedy algorithm that relies on an optimum solution at each iteration until the destination node visited [33]. Considering the behaviour of the DA, it should be directedweighted graph and the edges should be nonnegative. However, if the edges are negative, the actual shortest path cannot be obtained [34]. 
Input: An edge weighted connected graph $\mathrm{G}(\mathrm{V}$, $\mathrm{E}, \mathrm{w})$ where $\mathrm{w}: \mathrm{E} \rightarrow \mathrm{R}+$ and two vertices $\mathrm{s}, \mathrm{t}$. Output: A path from $s$ to $t$ with minimum total cost (shortest path)

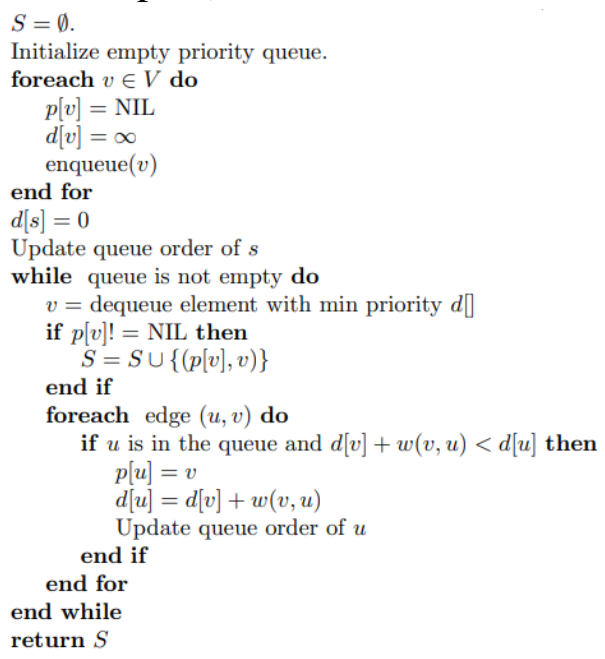

Fig. 6 Dijkstra's Shortest Path Algorithm

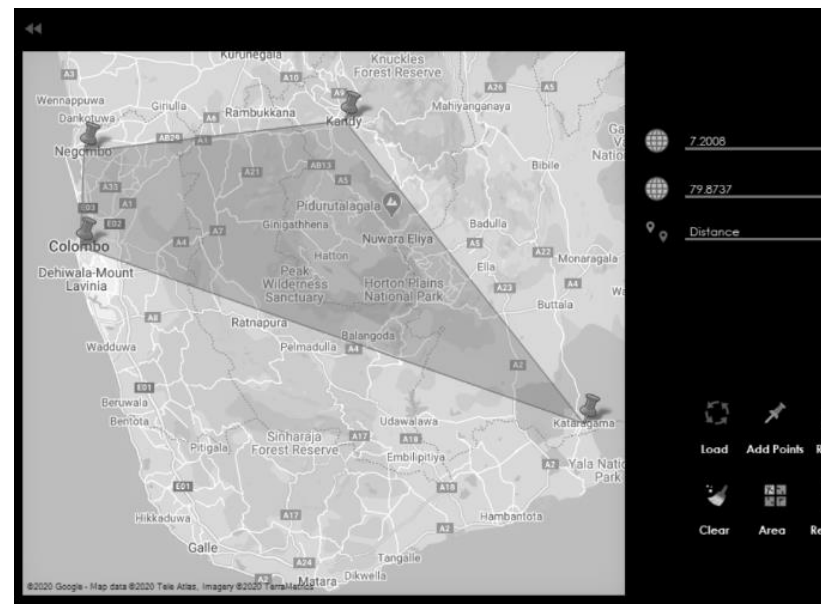

Fig. 7 Generate a Polygon Area on Specific GeoLocations

Considering all the above-mentioned algorithms and their processes, in order to provide more accurate geo-locations, calculate distance, find routes, and generate polygon areas, the proposed artefact was applied one of the most complex algorithms named “Dijkstra's Algorithm" (DA).
TABLE I

GEO-LOCATION COORDINATES

\begin{tabular}{|c|c|c|}
\hline Locations & Latitude & Longitude \\
\hline Colombo & $6.9271 \mathrm{~N}$ & $79.8612 \mathrm{E}$ \\
\hline Negombo & $7.2008 \mathrm{~N}$ & $79.8737 \mathrm{E}$ \\
\hline Kandy & $7.2906 \mathrm{~N}$ & $80.6337 \mathrm{E}$ \\
\hline $\begin{array}{c}\text { Kataraga } \\
\text { ma }\end{array}$ & $6.4135 \mathrm{~N}$ & $81.3326 \mathrm{E}$ \\
\hline \multicolumn{2}{|c}{} & \\
\hline
\end{tabular}

\section{Encryption and Decryption}

According to the ethical policies on confidentiality, almost every organizations or companies in the today world responsible for guaranteeing of confidentiality of information. In order to use for different marketing purposes, most of the organizations around the world, misuse personal and sensitive information of customers. Misuse of personal and private information is widely recognized as invasion of privacy. Therefore, when gathering private and sensitive information about people from the government of Sri Lanka, people may need to make sure that their private information will not be used in ways which they do not approve.

There was a time during the civil war in Sri Lanka, latitudes, longitudes, and coordinates were priceless information for both government and terrorists. Whoever has the accurate coordinates in the battlefield, they always won the advantage of the field. Therefore, when using above-mentioned sensitive information, we are bound legally and ethically to prevent the security breaches and protect secured information, the research applied "Base64" encrypting and decrypting methodology. 


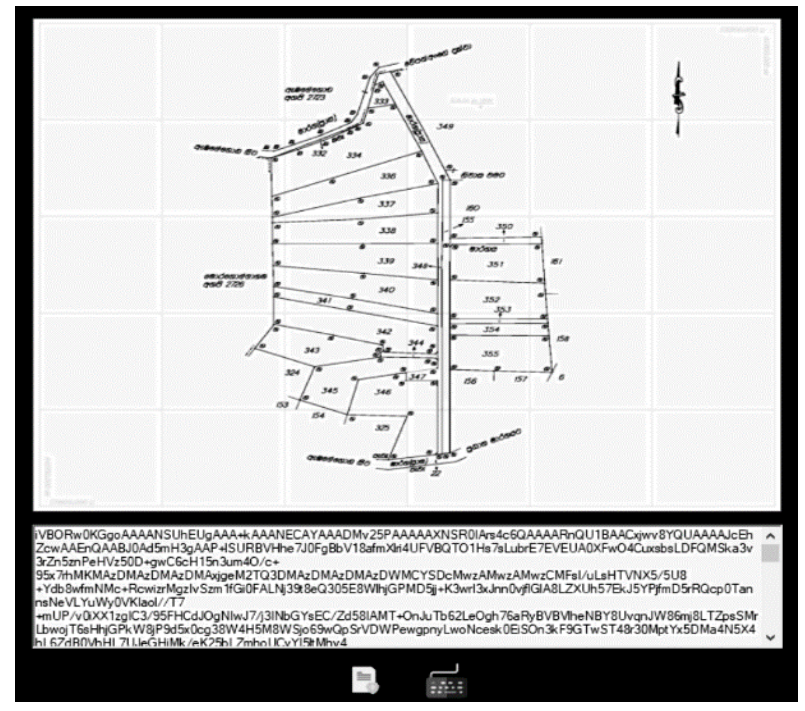

Fig. 8 Encrypting and Decrypting Cadastral Survey Plan Information

\section{Tenement List}

TABLE 2

SAMPLE TENEMENT LIST DATABASE

\begin{tabular}{|c|c|c|c|c|}
\hline $\begin{array}{c}\text { Plan } \\
\text { No }\end{array}$ & $\begin{array}{c}\text { Lot } \\
\text { No }\end{array}$ & $\begin{array}{c}\text { Ext } \\
\text { ent }\end{array}$ & $\begin{array}{l}\text { Requi } \\
\text { sition } \\
\text { No }\end{array}$ & $\begin{array}{c}\text { Uniq } \\
\text { ue } \\
\text { No }\end{array}$ \\
\hline 3652 & 5 & 34 & 6814 & 2234 \\
\hline 1538 & 23 & 5 & 3256 & 6342 \\
\hline 768 & 11 & 83 & 413 & 325 \\
\hline 850 & 2 & 15 & 3674 & 2571 \\
\hline
\end{tabular}

When it comes to the Tenement List, it is used to identify the owner of a particular land and authenticate the ownership of the land. Thus, a platform was designed where Surveyors and Superintendent of Surveyors can manage imperative information such as Plan No, Lot No, Requisition No, Unique No, Extent, Name of the Land, Description, North, East, South, West, Remarks, Village, Minor Division, Divisional Secretariat Division, District, Province, Surveyed Date, Surveyed By, and the Designation.

\section{Recommendations for Future Considerations}

Technology has advanced in many ways within a period of years and it has changed, and impacted human interaction with community, communication, thinking, and interaction with the surrounding environment. Higher expectations and desires of human needs have led to a consistent advancement in technology and consequently, human lives depend on technology today. Based on the recommendations for further considerations and the measurement of the effectiveness of the artefact, facial recognition and speech recognition services could be proposed. In the end, it will be a platform, where everyone can voice their commands.

\section{Conclusion}

This report was aimed to gain experience about issues that surveyors and the government have been facing throughout the surveying process.

The proposed system was creatively designed and enforced for managing Bimsaviya, LRC, RDA and Private Cadastral Plans and Tenement List Information, Encoding and Decoding QR Codes, Encrypting and Decrypting Cadastral Survey Information, OTP Message Service, SSL Certification on Email, Live Mapping including Latitude, Longitude, Routes, Add Points, Area by Polygon, Load Locations, Clear and Remove Points, Live Charts and Report Generating by Revenue, Number of Lots, Extent and Topography, Open and Extract PDF to Word Format, Search and Highlight Texts, Screenshot Feature, Backup and Restore Database, Indicating Error Messages, Password Reset Options and System Validations such as Login Validation and Email Validation. 
To put the matter in a nutshell, the research consisted of and nurtured by descriptive statistics, survey acts, survey regulations, standing orders and many more ordinances and statutes prepared by the Survey Department of Sri Lanka.

Furthermore, the research was conducted according to an exploratory process to increase the efficiency of services, increase the overall satisfaction rate of customers and employees of the Survey Department of Sri Lanka.

\section{Acknowledgement}

I would like to express my gratitude to everyone who supported me throughout the research. I owe my deep gratitude to the Head of the Department of IT, Ms. Suranji Nadeeshani and Mr. Thilak De Silva for their guidance and motivation. The research could not have been possible without the kind support and guidance of Ms. Sachini Vindya Gunasekara who helped me with the proper guidance and sharing knowledge. I am thankful to everyone in the Survey Department and Mr. N.R.L Mendis (Rtd. Superintendent of Surveyors) who provided me with the facilities and knowledge being required for the research.

\section{References}

1) w. Survey Department of Srilanka, "Survey Department of SriLanka", Survey.gov.lk, 2020. [Online]. Available: https://www.survey.gov.lk/sdweb/home.php. [Accessed: 26- February- 2020].

2) C. D, Y. Kang and D. Kang, Icaci.org, [Online].

Available: https://icaci.org/files/documents/ICC_proce edings/ICC2001/icc2001/file/f11034.pdf. [Accessed: 09- March- 2020].
3) Choe, B., Kim, M., Lee, K. and Jeong, Y., 2005. [online] Core.ac.uk. Available at: <https://core.ac.uk/download/pdf/5116959 7.pdf> [Accessed 9 March 2020].

4) K. SOON, D. TAN and V. KHOO, Gdmc.nl, 2016. [Online]. Available:

http://www.gdmc.nl/3Dcadastres/literature 13Dcad_2016_33.pdf. [Accessed: 10March- 2020].

5) P. Enemark and P. Sevatdal, Fig.net, 1999. [Online].

Available: https://fig.net/resources/proceedings/1999/ figun/sessions/session2/enemark.pdf.

[Accessed: 13- March- 2020].

6) Choon, T., Hussin, D. and Oon, S., 2010. [online] Available at: $<$ https://www.researchgate.net/profile/Tan _Choon/publication/280545203_New_Cad astral_System_Towards_Planning_and_C onstruction_Sustainability/links/55b88197 08ae9289a08d5efc/New-Cadastral-

System-Towards-Planning-and-

\section{Construction-}

Sustainability.pdf?origin=publication_deta il> [Accessed 14 March 2020].

7) "Land Reform Commission", Lrc.gov.lk, 2020. [Online]. Available: https://lrc.gov.lk/index.php?lang=en.

[Accessed: 26- March- 2020].

8) "landsettledept", Landsettledept.gov.lk, 2020. [Online]. Available: http://www.landsettledept.gov.lk/web/inde x.php/en/component/content/article/2uncategorised/96-land-settlement. [Accessed: 26- March- 2020].

9) "Cadastral surveys and records of rights in land", Fao.org, 2020. [Online]. Available: http://www.fao.org/3/v4860e/v4860e03.ht m. [Accessed: 29- March- 2020].

10) "Cadastral Maps and Plans | Intergovernmental Committee on Surveying and Mapping", Icsm.gov.au, 2020. [Online]. Available: 
https://www.icsm.gov.au/education/funda mentals-mapping/types-maps/cadastralmaps-and-plans. [Accessed: 06- April2020].

11) Survey.gov.lk, 2020. [Online]. Available: https://www.survey.gov.lk/sdweb/pdf/dow nload/publications/survey\%20journel/The \%20Survey\%20Journal\%2077.pdf.

[Accessed: 06- April- 2020].

12) Survey.gov.lk, 2020. [Online]. Available: https://www.survey.gov.lk/sdweb/pdf/dow nload/publications/survey\%20journel/The \%20Survey\%20Journal\%2078.pdf.

[Accessed: 08- April- 2020].

13) Survey.gov.lk, 2020. [Online]. Available: https://www.survey.gov.lk/sdweb/pdf/dow nload/publications/survey\%20journel/The \%20Survey\%20Journal\%2079.pdf.

[Accessed: 15- April- 2020].

14) Survey.gov.lk, 2020. [Online]. Available: https://www.survey.gov.lk/sdweb/pdf/dow nload/publications/survey\%20journel/The \%20Survey\%20Journal\%2080.pdf.

[Accessed: 18- April- 2020].

15) Survey.gov.lk,2020.[Online].Available:htt ps://www.survey.gov.lk/sdweb/pdf/downl oad/publications/Mapping_Manual.pdf.

[Accessed: 18- April- 2020].

16) Survey.gov.lk, 2020. [Online]. Available: https://www.survey.gov.lk/sdweb/pdf/prof ormancereport/2019/2019-

\%20\%20English.pdf. [Accessed: 18April- 2020].

17) Survey.gov.lk, 2020. [Online]. Available: https://www.survey.gov.lk/sdweb/pdf/surv eydocuments/Survey\%20Act/Survey\%20 Act\%20English.pdf. [Accessed: 21- April2020].

18) Survey.gov.lk, 2020. [Online]. Available: https://www.survey.gov.lk/sdweb/pdf/surv eydocuments/Survey\%20Act/Survey\%20 Act\%20Regulation(e).pdf. [Accessed: 23April- 2020].
19) Survey.gov.lk, 2020. [Online]. Available: https://www.survey.gov.lk/sdweb/pdf/surv eydocuments/standing_Order/so_english.p df. [Accessed: 27- April- 2020].

20) Survey.gov.lk, 2020. [Online]. Available: https://www.survey.gov.lk/sdweb/pdf/surv eydocuments/UDA\%20regulation/uda $\% 20$ regulation $\% 20$ for $\% 20$ sub $\% 20$ divisions $\% 2$ 0of\%20land.pdf. [Accessed: 30- April2020].

21) AbuSalim, S., Ibrahim, R., Saringat, M., Jamel, S. and Wahab, J., 2020. Comparative Analysis between Dijkstra and Bellman-Ford Algorithms in Shortest Path Optimization. [online] Iopscience.iop.org. Available at: <https://iopscience.iop.org/article/10.1088 /1757-899X/917/1/012077/pdf> [Accessed 04 May 2020].

22) Sniedovich, M., 2006. Dijkstra's algorithm revisited: the dynamic programming connexion. [online] Matwbn.icm.edu.pl. Available at: $<$ http://matwbn.icm.edu.pl/ksiazki/cc/cc35 /cc3536.pdf> [Accessed 04 May 2020].

23) Khan, Z., 2016. Comparison of Dijkstra's Algorithm with other proposed algorithms. [online] Available at: $<$ https://www.researchgate.net/profile/Zaf ar-

Khan/publication/309771211_Comparison _of_Dijkstra\%27s_Algorithm_with_other _proposed_algorithms/links/5822f93f08ae ebc4f898315a/Comparison-of-Dijkstras-

Algorithm-with-other-proposedalgorithms.pdf?origin=publication_detail $>$ [Accessed 07 May 2020].

24) Sharma, Y., Saini, S. and Bhandhari, M., n.d. Comparison of Dijkstra's Shortest Path Algorithm with Genetic Algorithm for Static and Dynamic Routing Network. [online] Core.ac.uk. Available at: <https://core.ac.uk/download/pdf/2571363 6.pdf> [Accessed 08 May 2020]. 
25) Dijkstra Algorithm: Key to Finding the Shortest Path, Google Map to Waze", Medium, 2020. [Online]. Available:

https://medium.com/@yk392/dijkstraalgorithm-key-to-finding-the-shortestpath-google-map-to-waze-56ff3d9f92f0. [Accessed: 08- May- 2020].

26) HackerEarth. n.d. Shortest Path Algorithms Tutorials \& Notes । Algorithms | HackerEarth. [online] Available at: <https://www.hackerearth.com/practice/al gorithms/graphs/shortest-pathalgorithms/tutorial/> [Accessed 11 May 2020].

27) Baum, J., 2020.5 Ways to Find the Shortest Path in a Graph. [online] Medium. Available at: <https://medium.com/betterprogramming/5-ways-to-find-the-shortestpath-in-a-graph-88cfefd0030f $>$ [Accessed 11 May 2020].

28) Datta, S., n.d. Bellman Ford Shortest Path Algorithm | Baeldung on Computer Science. [online] Baeldung on Computer Science. Available at: $<$ https://www.baeldung.com/cs/bellmanford $>$ [Accessed 17 May 2020].

29) Sasaki, K., n.d. Illustration of Distributed Bellman-Ford Algorithm. [online] The First Cry of Atom. Available at: $<$ https://www.lewuathe.com/illustrationof-distributed-bellman-fordalgorithm.html> [Accessed 17 May 2020].

30) Jain, A., n.d. A* Algorithm | Introduction to the $A^{*}$ Seach Algorithm | Edureka. [online] Edureka. Available at: $<$ https://www.edureka.co/blog/a-searchalgorithm/\#whyastar> [Accessed 20 May 2020].

31) Wimmer, S. and Lammich, P., 2020. The Floyd-Warshall Algorithm for Shortest Paths. [online] Isa-afp.org. Available at: $<$ https://www.isa-
afp.org/browser_info/current/AFP/Floyd_ Warshall/document.pdf> [Accessed 20 May 2020].

32) Bukhori, D. and Dengen, N., 2019. Floydwarshall algorithm to determine the shortest path based on android. [online] Iopscience.iop.org. Available at: <https://iopscience.iop.org/article/10.1088 /1755-1315/144/1/012019/pdf> [Accessed 26 May 2020].

33) Chen, J., 2003. Dijkstra's Shortest Path Algorithm. [online] Fm.mizar.org. Available at: <https://fm.mizar.org/200311/pdf11-3/graphsp.pdf> [Accessed 26 May 2020].

34) Puthuparampil, M., n.d. REPORT DIJKSTRA'S ALGORITHM. [online] Cs.nyu.edu. Available at: $<$ https://cs.nyu.edu/courses/summer07/G2 2.2340-

001/Presentations/Puthuparampil.pdf> [Accessed 28 May 2020].

35) "Investors for Reservations", It.survey.gov.lk, 2020. [Online]. Available: http://www.it.survey.gov.lk/nsdi/lis/index_ igr.php. [Accessed: 20- Aug- 2020]. 